\title{
Qualitative and Quantitative Analysis of Paracetamol in Different Drug Samples by HPLC Technique
}

\author{
S. S. Narwade \\ Department of chemistry, \\ Dr. Babasaheb AmbedkarMarathwada University, Aurangabad (MH) India.
}

\begin{abstract}
HPLC is rapid more accurate,purity checking \& separation method of paracetamolin different drug sample as compare with standard reference\& sample solution within complies with Indian Pharmacopeia. This method is applicable to Forensic science laboratories also. It is very sensitive less time consumable but sharp peaks recorded. Chromatographic technique - stainless still column $20 \mathrm{~cm} \times 4.6 \mathrm{~mm}$ packed with ocadesilance bonded to porous silica 10 micrometer. Flow rates $0.2 \mathrm{ml} / \mathrm{min}$. at 20 micrometer loop injector \& spectrophotometer set at $272 \mathrm{~nm}$. Retention time of std 4-ammino phenol \& sample solution 4.388 \& 4.542 respectively. Labeled amount $102.86 \%$ of paracetamol was observed. The \% is indicated that the paracetamol is within limit of Indian pharmacopeia.

Identification: Sample given Indian pharmacopeia identification test for the presence of paracetamol.

KeyWords:Analysis, Chromatogram, Drug Sample, HPLC, Paracetamol, Retention time, Spectrophotometer
\end{abstract}

\section{Introduction}

Paracetamol, $\mathrm{N}$ (4hydroxy phenyl acetamideis analgesic and antipyretic drug.It is used to prevent fever, headaches \& colds. It is one of the major drug \& also used along with other drug. Paracetamol is part of the class of drug known as "aniline analgesic". So it is need to analyzeparacetamol quantitatively \&qualitatively. A lower dosage of additional non steroidal anti -inflametry drug to be used by minimizing over all side effect [1-3] Present work includes analysis of paracetamol. It is active metabolite of phenacetin\& not considered to be carcinogenic at therapeutic doses. Main aim of this study was to develop a new RP-HPLC [4-6] method for determination of sample and standard paracetamol from formulated tablet. This method has been reported for the analysis of paracetamol\& its combination in pharmaceuticals or in biological fluids. Paracetamol has been determined in combination with other drug's using UV -spectrophotometry [7-10]. Paracetamol (PARA) is chemically N-(4-hydroxy phenyl) acetamide (amide derivative). It functioned as a weak inhibitor of the synthesis of prostaglandins (PGs) [11]. However, invivo effects of paracetamol are similar to those of the selective cyclooxygenase-2 (COX-2) inhibitors [12]. Paracetamol also decreases PG concentrations invivo. Structure of Paracetamol (PARA) is shown in Fig. 1.

\section{Structre of paracetamol tablet}<smiles>CC(=O)Nc1ccc(O)cc1</smiles>

Figure -1

\section{Experimental}

Identification: Sample given Indian pharmacopeia identification test for the presence of paracetamol.

Paracetamol test for 4-aminophenol

Chromatographic technique

Stainless steel column $20 \mathrm{~cm}$ x $4.6 \mathrm{~mm}$ packed with ocadecysilance bonded to porous Silica 10 micrometer.

Mobile phase:

$0.01 \mathrm{M}$ Sodium Butanesulphate in a mixture of 85 volume of water,

15 volume of methanol and 0.4 volume of formic acid

Flow rate $0.2 \mathrm{ml}$ per minute. 
Spectrometer set at $272 \mathrm{~nm}$.

At 20 micrometer loop injector

\section{Preparation of standard test solution:}

Approximately 4-5 gm of standard 4- aminophenol was taken in silica crucible covered with glass funnel and evaporated with continually. A sublimate of white powder was formed. Accurately $0.25 \mathrm{mg}$ of sample was taken in $1000 \mathrm{ml}$ standard flask and $15 \%$ methanol was added up to the mark. $1 \mathrm{ml}$ of this solution was taken in $25 \mathrm{ml}$ standard flask diluted with methanol up to the mark. Filter this solution.Sonicator\& then used for HPLC. Peak was recorded.as Shown in Fig. 2.

\section{HPLC curve of Standard 4- amino phenol figure 2}

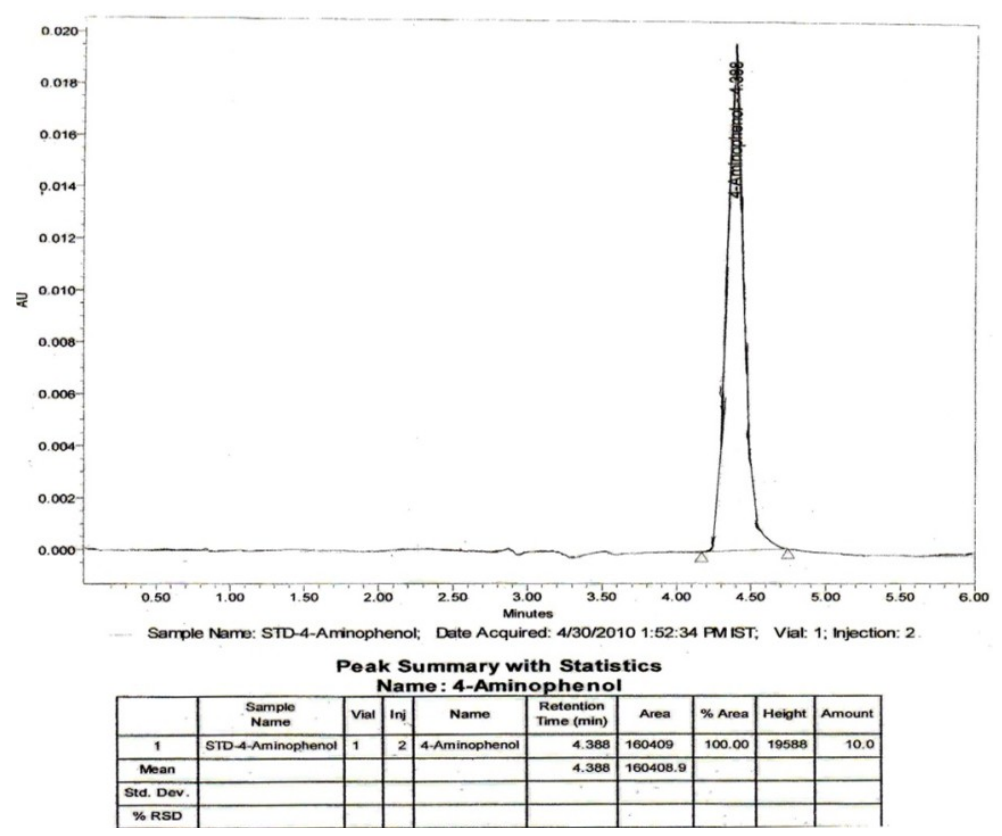

Preparation of paracetamol Sample solution $\left(\mathrm{C}_{6} \mathrm{H}_{7} \mathrm{NO}\right)$ :

$1.187 \mathrm{gm}$ of paracetamol was taken in $100 \mathrm{ml}$ standard flask \& $15 \%$ methanols were added up to the mark and than solution wassonictored. This solution was filtered an and then used for HPLC. The chromatogram was recorded.as shown in fig. 3 .

\section{HPLC curve Sample solution of 4- amino phenol figure 3}
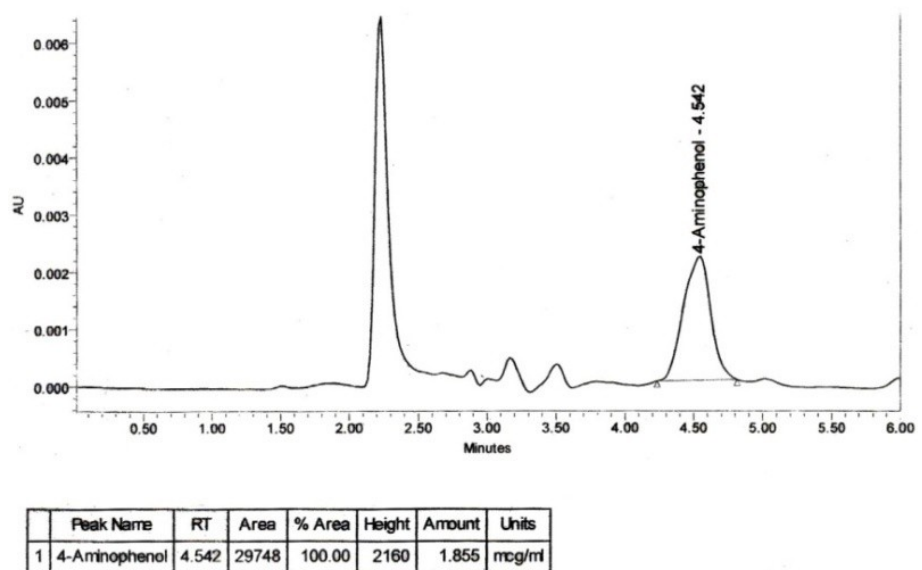


\begin{tabular}{|l|l|l|}
\hline Sr. no. & weight of paracetamol tablet & In gram \\
\hline 1 & weight of 20 tablets & 11.861 \\
\hline 2 & Average weight of 20tablet & 0.593 \\
\hline 3 & $\%$ deviation $=5 \%$ & 0.029 \\
\hline 4 & Lower limit & 0.563 \\
\hline 5 & Upper limit & 0.622 \\
\hline
\end{tabular}

\section{Result \& discussion}

In chromatogram obtained with the test solution, the area of any peak corresponding to 4- aminophenol is not grater than the area of peak in the chromatogram obtained with the reference solution. In the chromatogram obtained with the test solution peak with long retention time.

\section{Uniformity weight of tablets}

Sample complies with Indian pharmacopeia requirement for uniformity weigh of paracetamol tablet 1.

\section{Standard weight of paracetamol as shown in tablet 1}

\begin{tabular}{|l|l|l|l|}
\hline Sr. no. & weight of tablet(gm) & Sr. no. & weight of tablet(gm) \\
\hline 1 & 0.5924 & 11 & 0.5946 \\
\hline 2 & 0.5996 & 12 & 0.5934 \\
\hline 3 & 0.5947 & 13 & 0.6002 \\
\hline 4 & 0.5858 & 14 & 0.5853 \\
\hline 5 & 0.5993 & 15 & 0.5910 \\
\hline 6 & 0.5900 & 16 & 0.5853 \\
\hline 7 & 0.5876 & 17 & 0.6011 \\
\hline 8 & 0.5857 & 18 & 0.5951 \\
\hline 9 & 0.5962 & 19 & 0.5892 \\
\hline 10 & 0.6065 & 20 & 0.5913 \\
\hline
\end{tabular}

\section{Different weight of paracetamol as shown in tablet 2}

\section{Calculation:}

Weight of paracetamol $=$ sample area /standard area x standard weight / standard dilution / sample weight xaverage weight $x$ purity of sample.

$=0.5468 / 0.715 \times 10 / 1000 \times 20 / 0.1762 \times 0.5931 \times 100$

$=0.764 \times 0.01 \times 1135.07 \times 10 \times 10 \times 0.5931$

$=514.33 \mathrm{mg}$ of paracetamol

$=514.33 / 500 \times 100$

Weight of paracetamol $=102.86 \%$ of label amount. I.P. limit $95 \%$ to $105 \%$ of label amount)

\section{Dissolution of Paracetamol tablets:}

Sample complies with Indian pharmacopeia requirement for dissolution test.

$27.8 \mathrm{gm}$ of standard paracetamol was taken in $50 \mathrm{ml}$ standard flask and diluted with water. $1 \mathrm{ml}$ of this solution was taken in another $50 \mathrm{ml}$ standard flask and diluted up to the mark, using distilled water.

6 tablets was taken for sampling each tablet was dissolved in separate $900 \mathrm{ml}$ of distilled water and phosphate buffer PH 5.8 futher it was dissolved for 30 minute at 50 RPM, it becomes totally dissolved. $1 \mathrm{ml}$ of this solution was taken in $50 \mathrm{ml}$ standard flask and dilute with distilled water up to the mark. Absorbance was measured at $243 \mathrm{~nm}$.as shown in fig. 4. 


\section{UV graph figure 4}

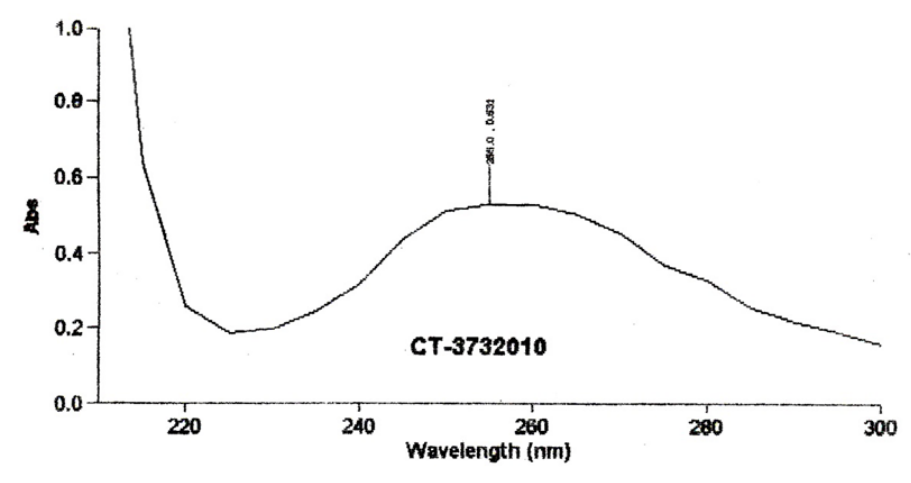

Figure -4

\section{Conclusion:}

On the basis of above observation, measured sample solution at $243 \mathrm{~nm}$. UV- Spectrophotometer the concentration of ParacetamolRs. Calculated the content of paracetamol was not less than $80 \%$ of the standard amount of Paracetamol. The observed percentage is indicated that the Paracetamol is within the limit of Indian pharmacopeia. The Paracetamol sample is indicated that there is rare side effect in the human body may be formed. High speed analysis, less time consumable checking purity of sample \& more intense peak recorded in RP-HPLC technique. It can be simultaneous determination for standard reference solution \& sample solution of Paraccetamol.

\section{Acknowledgment}

I would like to thanks DrRajendra P. Pawar, Associate Professor \& Head, Department of Chemistry, Deogiri College Auragnabad, Dr. SuryakantSapkal Asst. Prof. JNEC College, Aurangabad \& Dr.Prashant Ghosh, Dr. SujataPatil, Mr. Maruti Saundade with Cooperative Institute of MSS's College of Engineering \& Technology, Nagewadi.JALNA.

\section{References}

[1]. Goyal RS, Volt metric determination of paracetamol of 60-modified glassy carbon electrode electrochain. Acta. 2006, vol. 51, pp.3008-3012.

[2]. Singh DV, Bayers s, Phadke G and Jadhav M, Simultaneous determination of etodolac and acetoaminophen in tablet dosage from RP-lc. Chromatographia, 2009; vol. 69, pp. 1019-1023.

[3]. Grahm G and Scott K, Mechanism of paracetamol. Am. J. Ther., 2005, vol. 12, pp. 46-55.

[4]. Singh RM, Jami S, Ansari TA, et al. Determination of Rosuvastatin calcium in pharmaceutical dosage form by RP-HPLC method. Indian Drugs. 2005, vol. 42, pp. 98-101.

[5]. Singh SS, Sharma K, Patel H, et al. Estimation of Rosuvastatin in human plasma by HPLC Tandem Mass Spectroscopic method and its application to bioequivalence study. J BrazChem Soc. 2005, 16, pp. 944-950.

[6]. Thammera RK, Shitut NR, Pasikanti KK, et al. Determination of Rosuvastatin in rat plasma by HPLC and its application to pharmacy kinetic studies. Biomed Chromatogr. 2006, vol. 20, pp. 881-887.

[7]. Erk N, Onour F, Anal. Lett. 1997, vol. 30(6), pp. 1201-1210.

[8]. Chand HK, Grant DJW. Int.J.Pharma, 1989, vol. 57, pp. 117-124.

[9]. ReynoldsJEF. Mantindale the extra pharmacopeia 31stad, 1996; pp. 27-28 phamacetical press, London.

[10]. Sharma SK, Barot GB, Multani PJ. Development and validation of vierdot's and q-ratio method for the estimation of paracetamol, domperidone and flunarizine in solid oral dosage form. Int J Pharm Pharm Sci. 2013, vol. 5(2), pp. 347-351.

[11]. Karen methling et al Investigation of the invitro metabolism of Analgesic flupiritine, The American society for Pharmacology and experimental Therapeutics, 2008, pp. 1-49.

[12]. Available from URL http://www.drug2day.com/ index.php/drug/display/27971 (accessed on 12/10/2011). 